\title{
Detection and Molecular Characterization of Food Borne Pathogens from Ready to Eat Meat and Milk Products
}

\author{
S. Rathnapraba ${ }^{\text {* }}$, B. J. Shathish Sharma ${ }^{2}$, P. Kanagaraju ${ }^{3}$, \\ S. Meignanalakshmi ${ }^{4}$ and S. Manoharan ${ }^{5}$ \\ ${ }^{1}$ Vaccine Research Centre, Viral Vaccines, Centre for Animal Health Studies, \\ TANUVAS, Madhavaram Milk Colony, Chennai-51, India \\ ${ }^{2}$ Globion India Private Ltd., Hyderabad, India \\ ${ }^{3}$ Livestock Farm Complex, VC\&RI, Tirunelveli 627 358, India \\ ${ }^{4}$ Department of Animal Biotechnology, MVC, Chennai, India \\ ${ }^{5}$ Vaccine Research Centre, Bacterial Vaccines, Centre for Animal Health Studies, \\ TANUVAS, Madhavaram Milk Colony, Chennai-51, India \\ *Corresponding author
}

\section{A B S T R A C T}

\begin{tabular}{|l|}
\hline K e y w o r d s \\
$\begin{array}{l}\text { Food-borne } \\
\text { pathogens, ready to } \\
\text { eat (RTE) food } \\
\text { products, PCR } \\
\text { detection }\end{array}$ \\
\hline Article Info \\
\hline $\begin{array}{l}\text { Accepted: } \\
\text { 05 April 2020 } \\
\text { Available Online: } \\
\text { 10 May 2020 }\end{array}$ \\
\hline
\end{tabular}

Foodborne illness still remains a major threat to public health. Among the various pathogens causing food borne outbreaks, Salmonella sps, Stapylococcus aureus, Bacillus cereus, Campylobacter sps have been incriminated for majority of outbreak cases. Now - a - days consumption of minimally processed ready to eat (RTE) food products increases the risk of food borne diseases. The aim of the present investigation was to detect the presence of FSSAI notified six food pathogens from ready to eat food products. A total of 250 samples (including milk, milk products, meat and meat products) were screened for the presence of food-borne bacterial pathogens like Staphylococcus aureus, Bacillus cereus, Campylobacter jejuni, Streptococcus sp and Salmonella sp on selective medium. Further, culture positive colonies were screened by colony morphology, gram staining, biochemical analysis and molecular methods. Antibiotic susceptibility test was performed for all isolates of Staphylococcus aureus, Bacillus cereus and Streptococcus spp. The results revealed that the Staphylococcus aureus had $100 \%$ resistant against Vancomycin, Methicillin and Penicillin antibiotics and Bacillus cereus isolates had 100\% resistant against Vancomycin and Penicillin antibiotics and $100 \%$ sensitive towards Methicillin. Whereas the Streptococcus sp. shows 100\% resistant against Gentamicin, Streptomycin, Tetracycline and Ciprofloxacin. The prevalence of multidrug resistant pathogenic isolates in ready to eat food products may act as potential source of foodborne intoxication under favourable conditions which need to be addressed.

\section{Introduction}

Food safety is increasingly becoming an important public health issue, as foodborne diseases present a widespread public health problem globally. Among the various pathogens causing food borne outbreaks,
Salmonella sps, Staphylococcus aureus, Bacillus cereus, Campylobacter sps have been the major cause for the foodborne illness. Rapid and precise monitoring and detection of foodborne pathogens are the most effective ways to control and prevent foodborne illnesses. 
Traditional routine detection methods of these pathogens are based on culture dependent assays, including enrichment, chromogenic media and biochemical confirmation.

Although these methods are effective and remain the golden standards, they are rather time consuming, labour-intensive and sometimes complicated (Ding et al., 2017 and Li et al., 2016).

Moreover, conventional culture-based methods fail to detect viable but nonculturable (VBNC) cells which may introduce a serious crisis to food safety and public health (Zhao et al., 2014). In recent decades, molecular methods such as PCR have gained much attention for pathogen detection because they are simpler and faster compared to conventional culture methods (Mandal et al., 2011).

Minimally processed ready to eat (RTE) food products are increasingly used for consumption which increases the risk of food borne intoxications globally. Under these circumstances the present study was aimed to investigate the incidence and molecular detection of foodborne bacterial pathogens in ready to eat milk and meat products.

\section{Materials and Methods}

Samples collection and screening for foodborne bacterial pathogens

Ready to eat food products ( $\mathrm{n}=250)$ including poultry meat and poultry products, milk and milk products, packed ready to eat food, frozen food etc., procured from retail outlets in and around Chennai were utilised in the study. The food samples were screened for the presence of foodborne bacterial pathogens like Staphylococcus aureus, Salmonella sps, Streptococcus sps, Bacillus cereus and Campylobacter sps on Mannitol Salt agar
(MSA), Xylose Lysine Deoxycholate agar (XLD), blood agar base supplemented with strepto supplement, Mannitol egg yolk polymyxin (MYP) medium and Muller Hinton $(\mathrm{MH})$ media at $42^{\circ} \mathrm{C}$ for selective isolation of the above pathogens respectively.

The presumptive culture positive colonies were screened by colony morphology, gram staining, biochemical analysis and molecular methods. Biochemical characterization and Gram's staining of each presumptive colony of Staphylococcus aureus, Salmonella sps., Streptococcus sps., Campylobacter jejuni and Bacillus cereus isolates were done using specific Himedia biochemical test kit using HiStaph identification kit-KB004, HiSalmonella identification kit-KB011, HiStrep identification kit- KB005A and HiBacillus identification kit-KB013 respectively.

\section{Reference strains}

The reference strains procured from American type culture collection (ATCC) viz., Staphylococcus aureus (ATCC BAA 976),Salmonella enterica (ATCC 13076), Streptococcus sp. (ATCC 12392), Bacillus cereus ATCC 11778 and Campylobacter sps (ATCC 33291) were used as positive control for standardization of polymerase chain reaction (PCR) protocols.

\section{DNA extraction}

Overnight culture $(1 \mathrm{ml})$ was centrifuged at $10000 \mathrm{rpm}$ for 3 minutes, the pellet was suspended in $1 \mathrm{ml}$ of tris - EDTA buffer (TE buffer $\mathrm{pH}-8$ ), centrifuged at $10000 \mathrm{rpm}$ for 3 minutes. The final pellet was suspended in $20 \mu 1$ of Nucleuses free water (NFW) and boiled for 10 minutes, centrifuged at 10000 rpm for 3 minutes and supernatant was used as DNA template for PCR. 


\section{Polymerase Chain Reaction and Sequencing}

DNA isolated from the culture positive samples was used as templateand PCR was performed by targeting fem A, Inv A, tuf, cytolethal toxin and HL gene of Staphylococcus aureus (296 bp),Salmonella enterica (275 bp), Streptococcus spp. (196 bp), Campylobacter jejuni (192 bp)and Bacillus cereus (185 bp) respectively using published/designed primers as given in table1. The amplified products are checked in agarose gel electrophoresis. The PCR purified samples $(\mathrm{n}=5)$ (Qiagen gel extraction kit, Germany) were subjected to sequencing (Eurofins Genomics India Pvt. Ltd., Bengaluru, India) and analysed using DNA Star Laser gene V. 7.0 software. The phylogenetic tree was constructed with 1000 bootstrap value using a Maximum Likelihood method with MEGA software version 6.0.

\section{Antibiotic susceptibility test}

All the isolates of the selected food pathogens were tested for their antibiotic susceptibility pattern using disc diffusion method against a panel of ten antibiotics. The isolates were inoculated in Muller - Hinton broth and incubated at $37^{\circ} \mathrm{C}$ for $16-24 \mathrm{hrs}$. Turbidity of the overnight culture was adjusted to 0.5 McFerland standard and spread evenly over the Muller Hinton Agar (MHA) plates and the disc containing the specific concentrations of 10 antibiotics (HiMedia laboratories Pvt. Ltd., Mumbai) were placed on the surfaces of the agar plates and incubated at $37^{\circ} \mathrm{C}$ for overnight. The diameter of the inhibition zones were measured as per the manufacturer's instructions.

\section{Results and Discussion}

Out of 150 milk and milk products screened the percent positivity was $62,51,8,12$ and 2 for Staphylococcus aureus, Bacillus cereus, Streptococcus spp., Salmonella sps and Campylobacter spsby culture method. A representative culture plate of positive colonies along with the Gram stain images are shown in (Plate 1a-1d). The higher percent positivity for Staphylococcus aureus followed by Bacillus cereus in milk and milk products may be indicative of improper handling in production and packaging systems. Various authors studied the incidence level of food pathogens in dairy products and also suggested that the variation may be attributed to different sampling procedure and isolation techniques, (Jonkuviene et al., 2012, Kim et al., 2014, and Kumari and Sarkar 2017).A total of 100 meat samples including ready to eat chicken, mutton, beef and pork products were screened for the presence of Staphylococcus aureus, Bacillus cereus, Salmonella enterica, Streptococcus spp. and Campylobacter jejuni in their respective selective medium.

The percent positivity observed was 20,15,28,13 and 3 for Staphylococcus aureus, Bacillus cereus, Salmonella sps, Streptococcus spp. and Campylobacter jejuni by culture method respectively. The prevalence details of food pathogens in various meat products is represented in figure 1.Various researchers reported the prevalence of food pathogens in meat and meat products in chicken, beef and pork products (Gueven $e t$ al., 2006,Lubna et al., 2015, Hanson et al., 2011 Yang et al., 2016 and Soleimani et al., 2017). The variation may be due to the difference in sampling number, isolating methods and environmental parameters.

The presence of microorganisms in food is unavoidable and the recent proposed approaches for the detection of foodborne pathogens is mainly the culture based bacterial isolation and identification, but this is tedious and time consuming (Zhoa et al., 
2014). PCR is more than a promising method to detect the pathogenic bacteria with greater sensitivity and reliability than conventional culture methods and is considered to be a valuable alternative to the culture-based detection techniques due to its speed, limit of detection (LOD), sensitivity and specificity ( Rodríguez-Lázaro et al., 2007).In the present study, a total of 250 food products were subjected to PCR followed by genotypic characterization. The amplified product of Fem A, Tuf, haemolysin (HL) toxin and Cytolethal distendingtoxin A genes for Staphylococcus aureus, Streptococcus sps, Bacillus sps and Campylobacter sps was presented in plate $2 \mathrm{a}-\mathrm{d}$ respectively.

On phylogenetic analysis, 6 isolates of Staphylococcus aureus from milk products had 99\% homology with Staphylococcus aureus (AP014921.1). The 9 isolates of Bacillus cereus (Genbank accession numbers MH029496 - MH029501 and MH 046796 MH 046799) had94\% homology with Bacillus cereus (CP009968.1) and 3 isolates of Streptococcus sp. had $98 \%$ homology with the other Genbank sequence Streptococcus anginosus (KY275175.1). Further, 11 Staphylococcus aureus isolates from meat products (MH 509937, MH 509939, MH
509938, МH 460411, MH 460410, MH 460417, MH460416, MH 460415, MH 460414, MH 460413 and $\mathrm{MH}$ 460412) were obtained with $99 \%$ sequence homology. The phylogenetic tree was constructed based on the fem A gene sequences of $S$. aureus isolates from meat samples along with other coagulase negative Staphylococci species.

In the present study, the main cluster grouped several $S$. aureus strains and these strains are homologous to those from meat products. Four of the $S$. aureus isolates form the close evolutionary relationship with the Staphylococcus aureus isolates from Australia and three of the isolates form close evolutionary relationship with the Greece isolates. The 5 isolates Bacillus cereus from meat products (MH 547207 chicken nuggets), (MH 547206 beef cubes), (MH 547205 pork), (MH 547204 meat balls) and (MH 547203 chicken kheema) had $99 \%$ sequence homology.

The emergence of multidrug resistance of foodborne bacterial pathogens can be a major health concern. There is a need for the study of antibiotic susceptibility of each isolate to recognize their resistance towards different antibiotics (Kiessling et al., 2002).

Table.1 Details of primers used in the study

\begin{tabular}{|c|c|c|c|c|c|c|}
\hline $\begin{array}{l}\text { S. } \\
\text { No }\end{array}$ & $\begin{array}{l}\text { Name of the } \\
\text { organism }\end{array}$ & $\begin{array}{l}\text { Primer Sequence } \\
\left(5^{\prime}-3^{\prime}\right)\end{array}$ & $\begin{array}{l}\text { Target } \\
\text { Gene }\end{array}$ & $\begin{array}{c}\text { Anneali } \\
\text { ng } \\
\text { Temp } \\
\left({ }^{\circ} \mathrm{C}\right)\end{array}$ & $\begin{array}{l}\text { Produ } \\
\text { ct Size } \\
\text { (bp) }\end{array}$ & Reference \\
\hline \multirow[t]{2}{*}{1.} & \multirow{2}{*}{$\begin{array}{l}\text { Staphylococcus } \\
\text { aureus }\end{array}$} & FP: TATGAGTTAAAGCTTGCTGAAGGTT & \multirow[t]{2}{*}{ Fem A } & \multirow[t]{2}{*}{58} & \multirow[t]{2}{*}{296} & \multirow{2}{*}{$\begin{array}{l}\text { Kwasaki et } \\
\text { al., } 2012\end{array}$} \\
\hline & & RP: TTACCAGCATTACCTGTAATCTCG & & & & \\
\hline \multirow[t]{2}{*}{2.} & \multirow{2}{*}{$\begin{array}{l}\text { Salmonella } \\
\text { species }\end{array}$} & FP: TATCGCCACGTTCGGGCAA & \multirow[t]{2}{*}{ Inv A } & \multirow[t]{2}{*}{60} & \multirow[t]{2}{*}{275} & \multirow{2}{*}{$\begin{array}{l}\text { Rahn et al., } \\
1992\end{array}$} \\
\hline & & RP: TCGCACCGTCAAAGGAACC & & & & \\
\hline \multirow[t]{2}{*}{3.} & \multirow{2}{*}{$\begin{array}{l}\text { Streptococcus } \\
\text { species }\end{array}$} & FP: GTACAGTTGCTTCAGGACGTAT & \multirow[t]{2}{*}{ Tuf } & \multirow[t]{2}{*}{57} & \multirow[t]{2}{*}{197} & \multirow{2}{*}{$\begin{array}{l}\text { Picard et } \\
\text { al., } 2004\end{array}$} \\
\hline & & RP: ACGTTCGATTTCATCACGTTG & & & & \\
\hline \multirow[t]{2}{*}{4.} & \multirow[t]{2}{*}{ Bacillus cereus } & FP: CTGTAGCGAATCGTACGTATC & \multirow{2}{*}{$\begin{array}{l}\text { Hemolysin } \\
\text { gene }\end{array}$} & \multirow[t]{2}{*}{54.5} & \multirow[t]{2}{*}{185} & \multirow{2}{*}{$\begin{array}{l}\text { Wang et } \\
\text { al., } 1997\end{array}$} \\
\hline & & RP: TACTGCTCCAGCCACATTAC & & & & \\
\hline \multirow[t]{2}{*}{5.} & \multirow{2}{*}{$\begin{array}{l}\text { Campylobacter } \\
\text { sps }\end{array}$} & FP: GCTAATGGAGGAACAGATGTAGG & \multirow{2}{*}{$\begin{array}{l}\text { Cytolethal } \\
\text { distending } \\
\text { toxin A }\end{array}$} & \multirow[t]{2}{*}{55} & \multirow[t]{2}{*}{192} & \multirow[t]{2}{*}{ This study } \\
\hline & & RP: TCCGCTTGCTTGAGTTGC & & & & \\
\hline
\end{tabular}




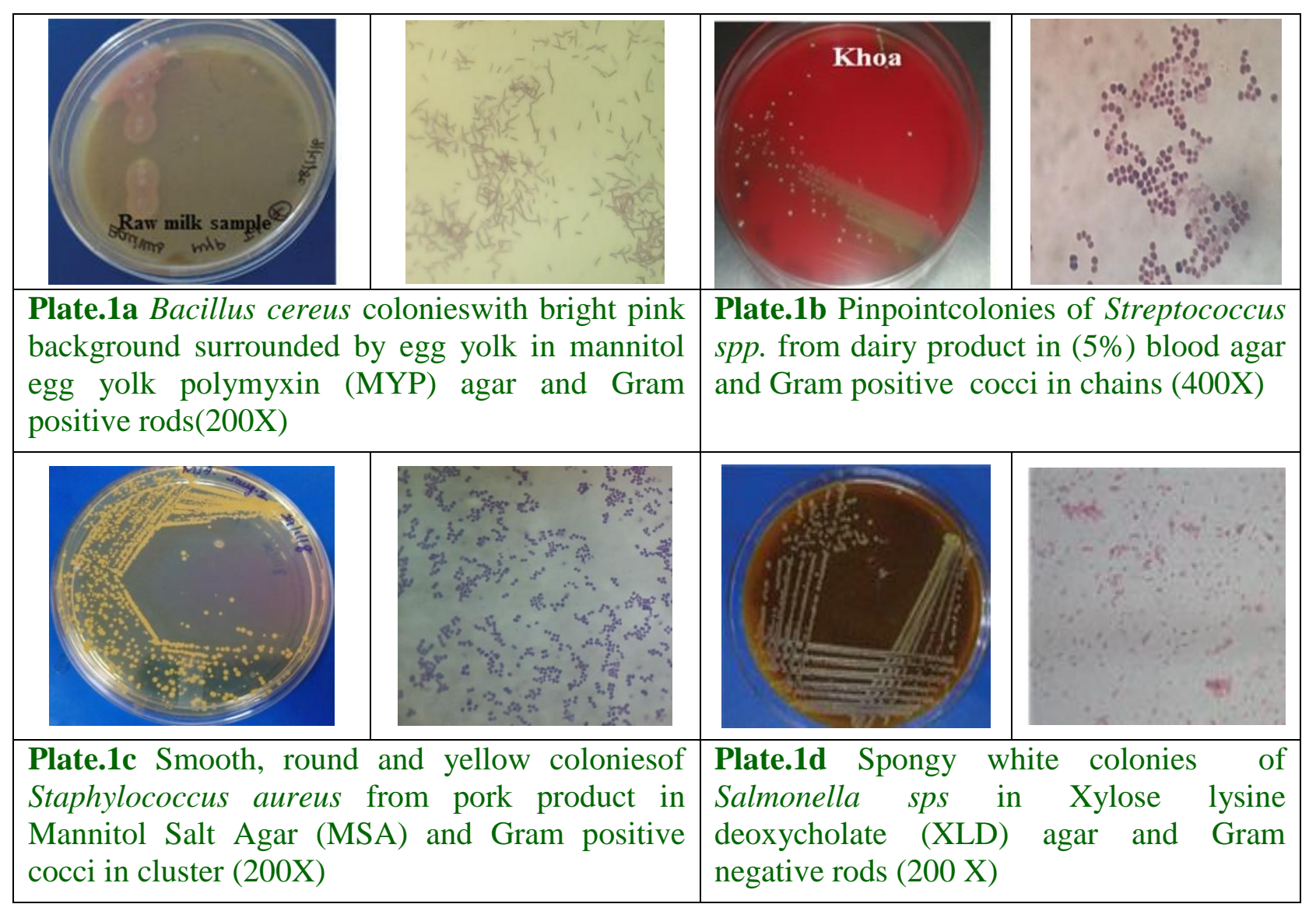

\begin{tabular}{|l|lllllllllll|}
\hline & 5 & &
\end{tabular}



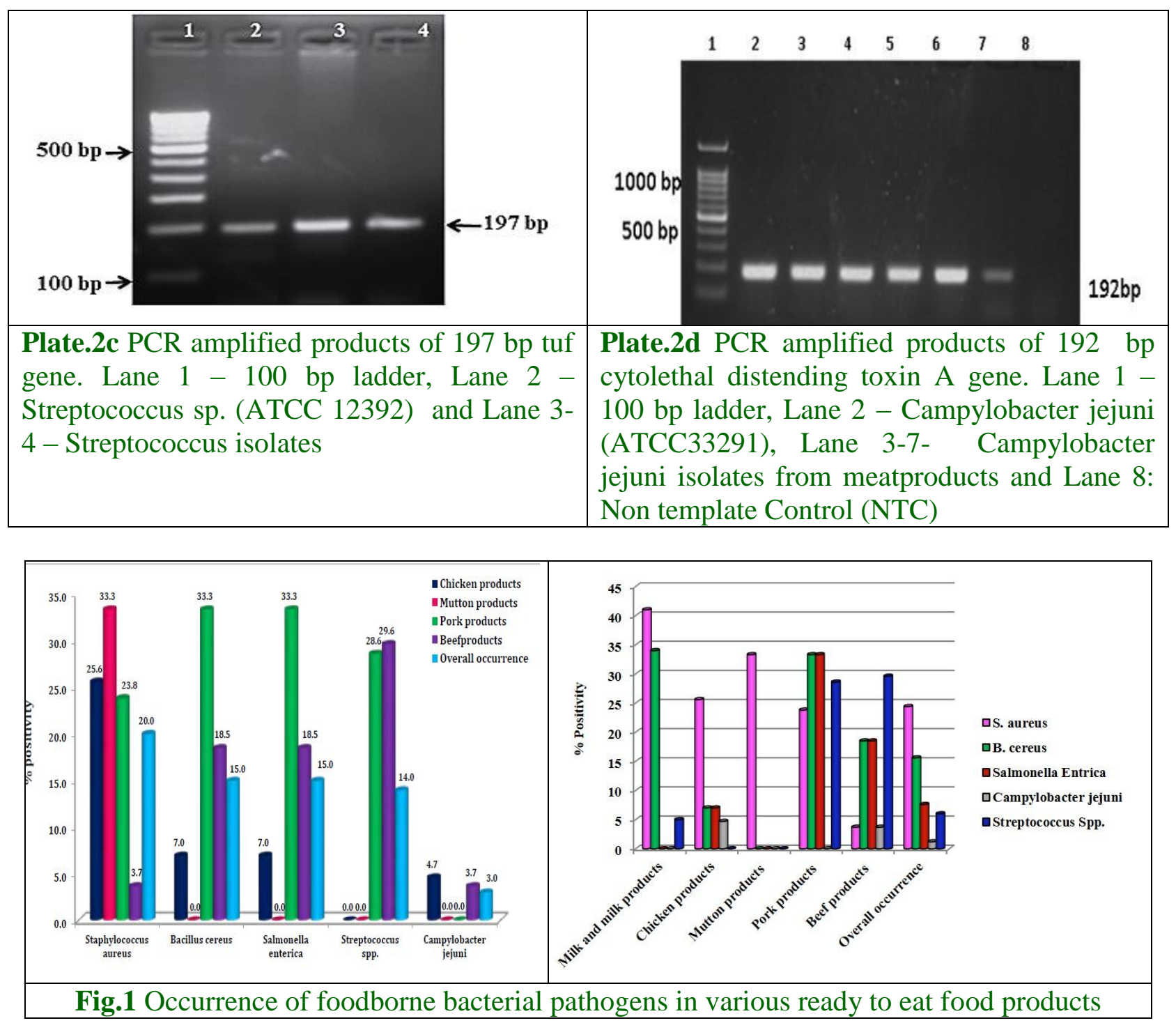

On antibiotic sensitivity assay, almost all the isolates obtained from meat amn milk showed multidrug resistance towards various antibiotics. Staphylococcus aureus exhibited $100 \%$ resistant Vancomycin, Methicillin and Penicillin. Bacillus cereus isolates showed $100 \%$ resistant against Vancomycin and Penicillin antibiotics and Streptococcus $s p$. showed $100 \%$ resistant against Gentamicin, Streptomycin, Tetracycline and Ciprofloxacin. The higher resistance of isolates to Penicillin, Tetracycline and Erythromycin in the present study may be attributed to the fact that these are the commonly used antibiotics for treatment in livestock and poultry.Variation in the antimicrobial resistant pattern of the isolates may be due to variation in concentration of the antibiotics used, drug resistance transfer and overall use of antibiotics.

Hence from the present study its is clearly indicated that, the ready to eat food products can act as significant source of antibiotic resistance microbial strains as potential cause for food borne intoxications. The toxin gene specific PCR rapidly detects the food pathogens from ready to eat meat products for precise monitoring in prevention of food borne intoxications. 


\section{Acknowledgment}

The authors greatly acknowledge Department of Biotechnology (DBT), GOI, New Delhi for funding and Tamil Nadu Veterinary and Animal Sciences University (TANUVAS), Chennai-51 for providing infra structural facilities to carry out this work.

\section{References}

Ding, T., Y. Suo, Z. Zhang, D. Liu, X.Ye, Chen, S., and Zhao, Y. 2017. A multiplex RT-PCR assay for $S$. aureus, L. monocytogenes and Salmonella spp. detection in raw Milk with pre-enrichment. Frontiers in microbiology, 8: 989.

Gueven, K., M.B. Mutlu and Avci. O. 2006. Incidence and characterization of Bacillus cereus in meat and meat products consumed in Turkey. Journal of Food Safety, 26(1): 30-40.

Hanson, B.M., A.E. Dressler, A.L. Harper, R.P. Scheibel, S.E. Wardyn, L.K. Roberts, J.S. Kroeger and Smith. T.C. 2011. Prevelance of Staphylococcus aureus and methicillin-resistance Staphylococcus aureus (MRSA) on retail meat in Iowa. The Journal of Infection and Public Health. 4(4): 169-174.

Jonkuviene, D., J. Salomskiene, R. Zvirdauskienè and Narkevicius, R. 2012. Determining differences in characteristics of Bacillus cereus isolated from various foods. Veterinary medicine and zootechnics. 60(82): 22-29.

Kawasaki, S., K. Kusano, R. Arai, T. Komeda, K.N. Horikoshi and S. Kawa moto. 2012. Multiplex PCR of Salmonella spp., Listeria monocytogenes, Escherichia coli and Staphylococcus aureus in processed foods using (TA10) simultaneousgrowth in broth. The Journal of Food, Agriculture and Environment 10 (3,4): 261-266.

Kiessling, C.R., J.H. Cutting, M. Loftis, W.M. Kiessling, A.R. Dutta and Sofos, J.N. 2002. Antimicrobial resistance of food-related Salmonella isolates, 1999-2000. Journal of Food Protection.65: 603-608.

Kumari, S. and Sarkar, P.K. 2017. Qualitative risk assessment of human exposure to Bacillus cereus group associated with household refrigerated storage ofpasteurized milk in India. Indian Journal of Dairy Science.70(2): 186192

Li, F., G.Xie, B.Zhou, P.Yu, S.Yu, Z. P. Aguilar and $\mathrm{Xu}, \mathrm{H}$. 2016. Rapid and simultaneous detection of viable Cronobacter sakazakii, Staphylococcus aureus, and Bacillus cereus in infant food products by PMA-mPCR assay with internal amplification control. Food Science and Technology, 74, 176-182.

Lubna. S.A., Harrington Wells and Mohammed K. Fakhr. 2015. Staphylococcus aureus is more prevalent in retail beef livers than in pork and other beef cuts. The Journal of Pathology. 4(2): 182-198.

Mandal, P., A.Biswas, K.Cho and Pal, U. 2011. Methods for rapid detection of foodborne pathogens: An overview. American Journal of Food Technology, 6: 87-102.

Picard F.J, K. Danbing, D.K. Boudrreau, M. Boissinot, A. Huletsky, D. Richard, M. Ouellette, P.H. Roy and Bergeron, M.H. 2004. Use of tuf sequences for genus-specific PCR detection phylogenetic analysis of 28 Streptococcal species. Journal of Clinical Microbiology. 42: 3686-3695.

Rahn K., S.A. De Grandis, R.C. Clarke, S.A. McEwen, J.E. Galán, C. Ginocchio, R. 
Curtiss 3rd, Gyles $\quad$ C.L.1992. Amplification of an invA gene sequence of Salmonella typhimurium by polymerase chain reaction as a specific method of detection of Salmonella. Molecular and Cellular Probes. 6(4):271-9.

Rodríguez-Lázaro, D., B. Lombard, H. Smith, A.Rzezutka, M.D'Agostino, R.Helmuth, A.Schroeter, B. Malorny, A. Miko, and Guerra, B. 2007. Trends in Analytical Methodology in Food Safety and Quality: Monitoring Microorganisms and Genetically Modified Organisms. Trends Food Sci. Technol. 18: 306-319.

Soleimani, M., H. Hosseini, Z. Pilever, M. Mehdizadeh and Carlin, F.2017. Prevelance, molecular identification and characterization of Bacillus cereus isolated from beef burgers. Journal of Food Safety. 38(1).

Wang, R.F., W.W. Cao and Cerniglia. C.E. 1997. A universal protocol for PCR detection of 13 species of foodborne pathogens in foods. Journal of Applied Microbiology, 83(6): 727-736.

Yang, S., X. Pei, G. Wang, L. Yan, J. Hu, Y. $\mathrm{Li}, \mathrm{N} . \mathrm{Li}$ and Yang. D. 2016. Prevalence of food-borne pathogens in ready to eat meat products in seven different Chinese regions. Food Control. 65: 92-98.

Zhao, X., C. W. Lin, J.Wang, and Oh, D. H. (2014). Advances in rapid detection methods for foodborne pathogens. Journal of Microbiology and Biotechnology, 24: 297-312.

\section{How to cite this article:}

Rathnapraba. S, B. J. Shathish Sharma, P. Kanagaraju, S. Meignanalakshmi and Manoharan. S. 2020. Detection and Molecular Characterization of Food Borne Pathogens from Ready to Eat Meat and Milk Products. Int.J.Curr.Microbiol.App.Sci. 9(05): 944-951. doi: https://doi.org/10.20546/ijcmas.2020.905.104 